United States valuable research information obtained by United States scientists in visiting other countries. The project will also take account of the problem of scientific communication as influenced by the training of scientists and of the needs of teachers, administrators and seience writers, which may be quite different from those of the research worker. An advisory committee has been formed to assist the Institute in providing liaison among allied biological groups.

\section{Funds for Industrial Research in the United States}

A PRELIMINARY report issued by the Nationa Science Foundation indicates that funds for research and development by industry in the United States amounted in 1959 to 9,400 million dollars, an increase of 15 per cent on 1958 , and the total is expected to reach 10,000 million dollars in 1960 (Reviews of Data on Research and Development, No. 24. N.S.F. 60-61. Washington 25, D.C., December 1960). Of the total, 5,400 million dollars came from federal funds, an increase of 17 per cent, whereas that financed by industry itself increased by 12 per cent. Expenditure on fundamental research was 344 million dollars, an increase of 17 per cent on 1958. Three-quarters of the Federal contribution went to two industries heavily engaged in research and development projects concerned with missiles, rockets and satellites, the aircraft industry alone receiving 2,500 million dollars, and the other industry, electrical equipment and communication, 1,600 million dollars.

\section{Computing Chemical Plant Automation}

The first British-produced digital computing system to be used to control a chemical process without human intervention has been ordered by Imperial Chemical Industries, Ltd., for use in their chemical plant at Fleetwood, Lancs. The machine concerned is the Ferranti Argus computer, which, because it uses only solid-state electronic elements, is deemed reliable enough to operate in relatively 'docile' chemical processes without a constant human monitor. It is interesting to note that the computer is of the pluggable sequence type ; the 'plugs' in this case being small ferrite rods which alter the coupling between mesh points of a set of mutually orthogonal conductors. In line with recent thought, the Argus has facilities for time sharing, the acceptance and emission of analogue signals, and the capacity of accepting additional drum storage of up to 50,000 words. The Imperial Chemical Industries, Ltd., installation has the basic capacity of 1,024 orders and core storage for 1,024 words. More than 300 analogue signals of six different types can be read in and outputs to control 100 pneumatic valves are provided. The arithmetical speeds are such that 50,000 additions or 10,000 multiplications can be performed each second.

\section{Coal Research in Australia}

The Coal Research Division of the Commonwealth Scientific and Industrial Research Organization has during the past four years published an attraetive series of 16-pæige pamphlets (Coal Research in C.S.I.R.O., Nos. 1 (May 1957)-11 (August 1960). Melbourne: Commonwealth Scientific and Industrial Research Organization) at the rate of three a year, describing facets of its work. Presentation and style are excellent; the articles are brief, popularly written and broadly informative, yet technically precise. Directed towards industrial producers and users of coal, the series would appear to serve four purposes and these may be illustrated with reference to recent articles. The 'educative' function is represented at present by a series on macerals, potrological constituents of cosls roughly analogous to the minerals in rocks. Their nature and appearance and their influence on properties of coal are described with the aid of typical photomierographs. Descriptions of 'techniques' and of 'recent research work' are closely related to one another, though the emphasis differs greatly between general application and specific results according to the topic under discussion. Examples of the former are "Fluidization Technique", "Porosity Measurements", and fundamental methods of investigation such as "Molecular Still for Tar Distillation" and "High Sensitivity Gas Chromatography". Among the latter may be mentioned "Coal Structural Studies", "Coal Macerals in Solution", "Char Blending makes Better Coke" and "AirFlow in Cupolas"; the aim, methods used, type of information obtained, and likely applications or significance are all touched on. Finally, some articles might be regarded first and foremost as "surveys of a field', as "Coke Production and Cupola Practice", "Utilization of High-Ash and Small Coals" and "Pitch for Making Electrode Carbon". The lastmentioned article, for example, gives information on methods of preparation and properties required. Each issue concludes with abstracts of papers published by staff of the Coal Research Division. While the breadth of treatment assists understanding and is to be preferred to a parochial approach, the impression is sometimes created (since acknowledg. ment of work elsewhere is not made) that the techniques, methods of interpretation, and detailed findings alike originated in the Research Organiza. tion's laboratories. Sometimes this is so; but often the work described forms part of the world-wide advance, and the article is partly concerned with this broader advance. These pamphlets deserve attention and success for their competent attempt to 'sell' research in industry.

\section{Technological Development in Poland}

A RECEnt issue of the Review of the Polish Academy of Sciences (No. 2, 5, April-June 1960) contains a survey by $I$. Malecki of fifteen years of technology in Poland and one by T. Nowicki of the six-years work of the Polish Academy of Sciences' Institute of Basic Technical Problems founded in 1953. Dealing first with the starting up of technology in Poland after the War, and the reconstruction and development of its technicel brasis, Dr. Malecki describes the development of particular industries, including transport and communications. Power production increased by 310 per cent between 1946 and 1958 , production of cast iron and steel from $1,200,000$ tons and 1,900,000 tons, respectively, in 1948 , to $3,900,000$ tons and $5,600,000$ tons in 1958 . There were major advances in the engineering industry which represented 19 per cent of industrial production in 1958 compared with 13 per cent in 1938, and the output of the chemical industry rose nine-fold compared with 1938. The industry now provides 70 per cent of pharmaceuticals compared with 12.5 per cent in 1949. The Institute of Basic Technical Problems comprises eight scientific centres covering three main fields : electrotechnics, mechanics and technical physics, and includes departments for the theory of 